Ganz ähnlich steigen die Schmelzpuncte der Aether, welche eine und dieselbe fette Säure mit den verschiedenen diesen Säuren entsprechenden Alkoholen liefert. (Compt.rend. T.47. - Chem. Centrbl. 1858. No. 43.) B.

\title{
Cholesterin ist ein Alkohol, analog dem Aethal.
}

Nach Berthelot erhält man die Naphthen des Cholesterins, z. B. das stearinsaure, benzoësaure, buttersaure und essigsaure Cholesterin, durch 10stündiges Erhitzen desselben mit den genannten Säuren bei $200^{\circ} \mathrm{C}$. in zugesehmolzenen Glasröhren. Zur Entfernung der überschüssigen Säure verfährt man ganz so wie bei Darstellung der künstlichen Fette. (Ann. de Chim. et de Phys. Tom. XLI. pag. 221-253. 1854.) Man erhält so die neutralen Verbindungen, gemengt mit dem unverbunden gebliebenen Cholesterin, Zur Entfernung desselben kocht man das Ganze mit dem zehnfachen Gewicht Weingeist, welcher das Cholesterin leicht löst, auf die Cholesterinsalze aber kaum losend wirkt. Man giesst die weingeistige Lösung $a b$ und wiederholt mit dem Ungelösten 5 bis 6 Mal dieselbe Behandlung mit Weingeist. Dann löst man den Rückstand in Aether siedend auf und lässt erkalten, wo sich die Cholesterinnaphthen krystallinisch ausscheiden. So erhält man Verbindungen aus 1 Aeq. Cholesterin mit 1 Aeq. Säurehydrat minus 2 Aeq. Wasser. Mit Alkalilaugen bei $100^{\circ} \mathrm{C}$. behandelt, leisten die Cholesteride länger Widerstand als die Glyceride (die Fette), doch nach einer Einwirkung von 8 bis 10 Tagen werden auch sie vollständig zerlegt (verseift); man erhält wieder Cholesterin und das Alkalisalz der mit dem Aether des Cholesterins verbunden gewesenen Säure.

Berthelot stellte dar: 1) Essigsaures Cholesterin.

2) Buttersaures Cholesterin $=\mathrm{C}^{52} \mathrm{H}^{44} \mathrm{O}^{2}+\mathrm{C}^{8} \mathrm{H}^{8} \mathrm{O}^{4}$ $-2 \mathrm{HO}=\mathrm{C}^{52} \mathrm{H}^{43} \mathrm{O}, \mathrm{C}^{8} \mathrm{H}^{7} \mathrm{O}^{3}=\mathrm{C}^{60} \mathrm{H}^{50} \mathrm{O}^{4}$. Fast nectral, ziemlich schmelzbar, ein wenig löslich in heissem Alkohol.

3) Stearinsaures Cholesterin $=\mathrm{C}^{52} \mathrm{H}^{43} \mathrm{O}, \mathrm{C}^{36} \mathrm{H}^{35} \mathrm{O}^{3}$. Neutrale farblose kleine glänzende Nadeln, grösser als die des Stearins, wenig löslich in kaltem Aether, beinahe unlöslich in gewöhnlichem Weingeist, selbst in siedendem.

4) Benzoësaures Cholesterin $=\mathrm{C}^{52} \mathrm{H}^{43} \mathrm{O}, \mathrm{C}^{14} \mathrm{H}^{5} \mathrm{O}^{3}$. Neutrale glimmerglänzende Blättchen, die zwischen 125 und $130^{\circ} \mathrm{C}$. schmelzen; ziemlich löslich in Aether, sehr wenig löslich in siedendem Alkohol. 
Wahrscheinlich finden sich im menschlichen Körper mehrere solcher Cholesterinverbindungen, theils in normalen, theils in pathologischen Producten. Der Zimmtalkohol gehört $\mathrm{zu}$ derselben homologen Gruppe $\mathrm{C}^{2 \mathrm{n}} \mathrm{H}^{2 \mathrm{n}-8} \mathrm{O}^{2}$ als das Cholesterin, denn dieses ist $\mathrm{C}^{2} \cdot 26 \mathrm{H}^{2} \cdot 22 \mathrm{O}^{2}=$ $\mathrm{C}^{52} \mathrm{H}^{44} \mathrm{O}^{2}$, und der Zimmtalkohol ist $\mathrm{C}^{2} \cdot 9 \mathrm{H}^{2 \cdot 5} \mathrm{O}^{2}=$ C18H 1002. (Compt. rend. 9. Août 1858. pag. 263-264.)

Dr. H. Ludwig.

\section{Darstellung des Glycerins,}

Ferguson und Wilson verwendeten bei der Darstellung von Fettsäuren und Glycerin aus Palmöl Wasserdampf und Wärme als einzige Zersetzungsmittel. In das in einem Destillir-Apparate befindliche Palmöl wird Wasserdampf geleitet, der die Temperatur von $500^{\circ}$ bis $600^{\circ} \mathrm{F}$. hat. Das Glycerin und die Fettsäuren nehmen hierbei ihr Aequivalent Wasser auf und destilliren über. Man erhält in der Vorlage zwei Schichten, zu unterst das Glycerin und darüber die Fettsäuren. (Journ. of the soc. of arts. - Polyt. Centrbl. 1858. S. 1036.)

E.

\section{Bereitung des Murexids.}

Nach Clark hat man bei der Bereitung des Murexids Folgendes zu beachten: Die Alloxanlösung und das Ammoniak oder kohlensaure Ammoniak muss man kalt mit einander vermischen und das Ammoniak nach und nach der Alloxanlösung zusetzen, theils um Erwärmung zu vermeiden, theils um der Alloxanlösung Zeit zu lassen, die saure Beschaffenheit wieder anzunehmen. Die angemessen mit Ammoniak gesättigte Alloxanlösung erwärmt man auf $60-70^{\circ} \mathrm{C}$. und lässt darauf das Murexid durch Abkühlen krystallisiren. Die Alloxanlösung, welche hier gemeint.ist, erhält man, wenn Salpetersäure, mit gleichen Theilen Wasser verdünnt, bei $600 \mathrm{C}$. mit Harnsäure gesättigt wird. (Rep. of pat. inv. July 1858. pag. 41. - Polyt. Centrbl. 1858. S.1309.) E.

\section{Sepia.}

Dieser Farbstoff wird aus der. schwarzen Flüssigkeit des Tintenfisches bereitet. Man nimmt den Sack aus dem getödteten Thiere, drückt die Flüssigkeit heraus, trocknet sie so rasch wie möglich, weil sie leicht, fault, 